\title{
Preparing for a new generation of biologic therapies: understanding the development and potential of biosimilar cancer therapeutics
}

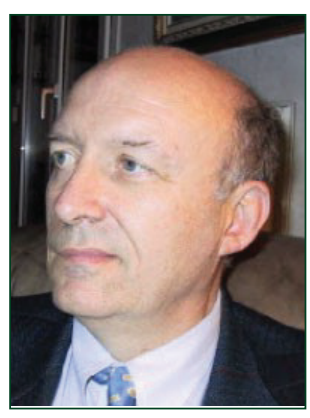

Bertrand Coiffier ${ }^{*}, 1$

\author{
"It is essential that as these treatments become \\ established, there is strict adherence to published \\ guidelines that recognize the increased stringency \\ required in validating biosimilar products, and \\ that these should not be confused with \\ their generic counterparts."
}

First draft submitted: 30 March 2017; Accepted for publication: 20 April 2017; Published online: 9 May 2017

Over recent years, monoclonal antibodies and other targeted biologic therapies have transformed the treatment paradigms and prognosis for many diseases compared with previously standard systemic therapies. Targeted therapies have shown particular clinical benefit in oncology, with agents including rituximab in CD20-positive hematological malignancies, trastuzumab in HER2-positive solid tumors and the antivascular EGF bevacizumab in a range of solid and often metastatic tumors. Clinical trials of these agents have demonstrated improved objective responses and/or improved survival [1-4]. Oncology treatment guidelines, including those from the US National Comprehensive Cancer Network [5] and European Society for Medical Oncology [6], now include targeted biologics as established cornerstones of clinical care.

However, the development and manufacture of therapeutic antibodies are based on biological processes that occur in living systems or organisms and require substantial expertise and investment in protein engineering [4]. The added complexity of producing biologic therapies, compared with 'traditional' chemically synthesized, small-molecule drugs, increases the cost of development. Indeed, it is estimated that about a third of all current pharmaceutical industry research and development expenditure is on biologics [7]. Similarly, around 35\% of current healthcare costs are related to targeted biologic drugs [8], with high prices thought to contribute to reducing availability and patient access [9]. Yet the demand for treatment continues to rise, driven by the increasing global cancer burden among an ageing population, and extended treatment times made possible by improvements in diagnosis, treatment and care [10]. Clearly, alternative biologic cancer treatments are needed to widen access to effective but high-cost modern drugs.

Today, many of the patents for targeted biologic therapies have expired, or are approaching their end, opening the door to a new era of biosimilar anticancer drugs with increased affordability, and therefore the potential for improved patient access. The recent approval of the rituximab biosimilar CT-P10 (Truxima ${ }^{\circledR}$ [CELLTRION; Incheon, Republic of Korea]) in Europe [11] and

'Hospices Civils de Lyon, Pierre-Benite, France

*Author for correspondence: Tel.: +33 478864 340; bertrand.coiffier@me.com

\section{KEYWORDS}

- biosimilars • oncology • targeted biologic therapies
Future Medicine ${ }_{\text {part of }}$ 
South Korea [12] represents the first monoclonal antibody biosimilar therapeutic to be approved for use in patients with hematological malignancies (or indeed any cancer indication).

Compared with 'generic' versions of smallmolecule drugs, which usually only require proof of product quality and bioequivalence versus their reference product, biosimilars need to meet much more extensive regulatory criteria for approval, not least as the efficacy of biological drugs is highly dependent on production and purification methodology [13-18]. As more biosimilars receive regulatory approval and reach the market, it will be increasingly important for healthcare providers to appreciate how biosimilars are developed and approved, in order that they gain trust in their effectiveness and safety. While the approval pathways for biosimilars are accelerated compared with their originator products, this process still necessarily involves detailed and direct comparison of biosimilars in terms of quality, pharmacokinetics, pharmacodynamics, efficacy, safety and immunogenicity [13-18].

In this supplement, we examine key aspects of biosimilar development and delivery that are essential to understanding the transition into the age of biosimilar cancer therapeutics. First, Professor Christian Buske and his coauthors examine the concept of biosimilars, the rationale for their development and the regulatory environment surrounding their approval and use [19]. Both the FDA and EMA have issued regulatory guidelines with stringent approaches to demonstrate biosimilarity through analytical, in vitro, nonclinical in vivo and clinical stages [13-18]. These steps contribute to the 'totality of evidence' considered by regulatory agencies when making their decisions on biosimilars. The rituximab biosimilar CT-P10 has recently been approved for use in chronic lymphocytic leukemia, follicular lymphoma and diffuse large B cell lymphoma (as well as in certain noncancer indications) [11]. The authors examine the 'totality of evidence' for this molecule using data from its nonclinical and clinical development programs.

If understanding the regulatory requirements of biosimilars represents the first hurdle to their acceptance, the next challenge is the relative paucity of information available about these agents, their use and efficacy in clinical practice. In the second article in this supplement, Professor Won Seog Kim et al. examine the current perceptions of healthcare providers, payers and other stakeholders regarding biosimilars and biosimilarity, and consider the important knowledge gaps that must be bridged for acceptance, increased confidence and safe use of this new class of treatments [20]. Recent positive experiences with CT-P13 (Remsima ${ }^{\circledR}$ [CELLTRION, Incheon, Republic of Korea], Inflectra ${ }^{\circledR}$ [Pfizer, NY, USA]), a biosimilar of the TNF inhibitor infliximab used to treat rheumatoid arthritis and other inflammatory disorders, highlights how the evolution of stakeholder perceptions may encourage the uptake of new biosimilars in cancer therapy, and guide their safe and effective use [21].

In the next article, Professor Kim and coauthors explore the clinical trial program for CT-P10 as a model for other biosimilar cancer therapeutics, examining the rationale for design of the CT-P10 clinical trials and briefly considering their results to date, including the demonstration of equivalence of pharmacokinetics and efficacy noninferiority for CT-P10 compared with rituximab in a Phase III study of treatment-naive advanced-stage follicular lymphoma [22]. Looking ahead, the authors also consider the ongoing development programs for the rituximab biosimilar candidates GP2013, PF-05280586 and ABP 798, as well as candidate biosimilars of cetuximab, trastuzumab and bevacizumab.

Finally, following the scientific principles that consistent structure informs consistent function, both FDA and EMA guidelines allow for extrapolation of biosimilar approval for additional, or all, the clinical indications of the reference product on the basis of successful demonstration of efficacy and safety in other indications, providing that this is scientifically justifiable [13-18]. Professor Michinori Ogura et al. examine the scientific data that provided the EMA with the justification to approve CT-P10 in all indications of reference rituximab, including chronic lymphocytic lymphoma, based on extrapolation of clinical data collected during clinical trials involving rheumatoid arthritis and follicular lymphoma populations [23].

The development of biosimilars builds upon the success of originator biologic therapies and will lead to greater competition and innovation in biologic therapy, allowing lower pricing and expanded access for patients. As postauthorization studies continue for CT-P10, and the many biosimilar cancer therapeutics that will 
undoubtedly follow, a growing body of evidence documenting the clinical equivalence of these agents is expected to emerge. It is essential that as these treatments become established, there is strict adherence to published guidelines that recognize the increased stringency required in validating biosimilar products, and that these should not be confused with their generic counterparts. Improved understanding of the development pathways for biosimilars will ease potential safety concerns, foster the confidence needed among healthcare providers, aid in regulatory approval and ultimately improve market uptake and patient access to biosimilars.

\section{Financial \& competing interests disclosure}

$B$ Coiffer has received personal fees from Gilead, Celgene, CELLTRION, Roche, MorphoSys, MedImmune, Mundipharma and Pfizer outside the submitted work. The author has no other relevant affiliations or financial involvement with any organization or entity with a financial interest in or financial conflict with the subject matter or materials discussed in the manuscript apart from those disclosed.

Writing assistance was utilized in the production of this manuscript. Medical writing support during the preparation of this article was provided by Duncan Campbell, PhD, CMPP (Aspire Scientific, Bollington, UK) and was funded by CELLTRION Healthcare Co., Ltd (Incheon, Republic of Korea).

\section{References}

1 Feldmann M, Maini RN. Anti-TNF therapy, from rationale to standard of care: what lessons has it taught us? J. Immunol. 185(2), 791-794 (2010).

2 Keating GM. Rituximab: a review of its use in chronic lymphocytic leukaemia, low-grade or follicular lymphoma and diffuse large B-cell lymphoma. Drugs 70 (11), 1445-1476 (2010).

3 Strand V, Kimberly R, Isaacs JD. Biologic therapies in rheumatology: lessons learned, future directions. Nat. Rev. Drug Discov. 6(1), 75-92 (2007).

4 Scott AM, Wolchok JD, Old LJ. Antibody therapy of cancer. Nat. Rev. Cancer 12(4), 278-287 (2012).

5 National Comprehensive Cancer Network. NCCN Clinical Practice Guidelines in Oncology. B-cell lymphomas v. 2.2017 www.nccn.org/professionals/ physician_gls/pdf/b-cell.pdf

6 Ghielmini M, Vitolo U, Kimby E et al. ESMO Guidelines consensus conference on malignant lymphoma 2011 part 1: diffuse large B-cell lymphoma (DLBCL), follicular lymphoma (FL) and chronic lymphocytic leukemia (CLL). Ann. Oncol. 24(3), 561-576 (2013).

7 Office of Health Economics Research. Briefing 54: what is the role of HTA for biosimilars? www.ohe.org/system/files/ private/publications $/ 396 \% 20-\% 20$ Role $\% 20$ of $\% 20$ HTA $\% 20$ for $\% 20$ Biosimilars $\% 20$ Mestre-Ferrandiz\%202014.pdf

8 IMS Institute for Healthcare Informatics. Medicines use and spending in the US.A review of 2015 and outlook to 2020 https://morningconsult.com/wp-content/ uploads/2016/04/IMS-Institute-US-DrugSpending-2015.pdf
9 Kelly CJ, Mir FA. Economics of biological therapies. BMJ 339, b3276 (2009).

10 Mariotto AB, Yabroff KR, Shao Y, Feuer EJ, Brown ML. Projections of the cost of cancer care in the United States: 2010-2020. J. Natl Cancer Inst. 103(2), 117-128 (2011).

11 CELLTRION Inc. Truxima. Summary of product characteristics. www.ema.europa.eu/ docs/en_GB/document_library/EPAR_-_ Product_Information/human/004112/ WC500222694.pdf

12 Generics and Biosimilars Initiative. Biosimilar rituximab approved in South Korea. www. gabionline.net/Biosimilars/News/Biosimilarrituximab-approved-in-South-Korea

13 European Medicines Agency. Guideline on similar biological medicinal products containing biotechnology-derived proteins as active substance: non-clinical and clinical issues. www.ema.europa.eu/docs/en_GB/ document_library/Scientific_ guideline/2015/01/WC500180219.pdf

14 European Medicines Agency. Guideline on similar biological medicinal products containing monoclonal antibodies - nonclinical and clinical issues. www.ema.europa. eu/docs/en_GB/document_library/ Scientific_guideline/2012/06/ WC500128686.pdf

15 European Medicines Agency. Guideline on similar biological medicinal products. www. ema.europa.eu/docs/en_GB/document_ library/Scientific_guideline/2014/10/ WC500176768.pdf

16 European Medicines Agency. Guideline on similar biological medicinal products containing biotechnology-derived proteins as active substance: quality issues (revision 1). www.ema.europa.eu/docs/en_GB/ document_library/Scientific_ guideline/2014/06/WC500167838.pdf
17 US Food and Drug Administration. Quality considerations in demonstrating biosimilarity of a therapeutic protein product to a reference product. Guidance for industry. www.fda. gov/downloads/drugs/guidances/ucm291134. pdf

18 US Food and Drug Administration. Scientific considerations in demonstrating biosimilarity to a reference product. Guidance for industry. www.fda.gov/downloads/drugs/guidances/ ucm291128.pdf

19 Buske C, Ogura M, Kwon H-C, Yoon SW. An introduction to biosimilar cancer therapeutics: definitions, rationale for development and regulatory requirements. Future Oncol. 13(15s), 5-16 (2017).

20 Kim WS, Ogura M, Kwon H-C, Choi D. Looking to the future and learning lessons from the recent past: changing stakeholder perceptions of biosimilars in cancer. Future Oncol. 13(15s), 17-29 (2017).

21 Han S, Kim S, Kim J. The pharmacoeconomic impact of biosimilar infliximab (CT-P13) in Europe from January 2015 to June 2016. Presented at: 12th Congress of the European Crohn's and Colitis Organisation. Barcelona, Spain, 15-18 February 2017.

22 Kim WS, Coiffier B, Kwon H-C, Kim S. Clinical development of CT-P10 and other biosimilar cancer therapeutics. Future Oncol. 13(15s), 31-44 (2017).

23 Ogura M, Coiffier B, Kwon H-C, Yoon SW. Scientific rationale for extrapolation across cancer indications: case study of CT-P10. Future Oncol. 13(15s), 45-53 (2017). 
